\title{
Qualidade da carne de fêmeas suínas alimentadas com diferentes concentrações de ractopamina na dieta
}

\author{
[Meat quality of gilts fed different ractopamine concentrations in diet] \\ P.H. Watanabe ${ }^{1}$, M.C. Thomaz ${ }^{2}$, L.A.F. Pascoal ${ }^{3}$, U.S. Ruiz ${ }^{2}$, E. Daniel ${ }^{2}$, A.B. Amorim ${ }^{4}$, \\ J. Cristani ${ }^{5}$, F.F. Castro ${ }^{2}$ \\ ${ }^{1}$ Universidade Federal do Ceará - Fortaleza - CE \\ ${ }^{2}$ Universidade Estadual Paulista - Jaboticabal, SP \\ ${ }^{3}$ Universidade Federal da Paraíba - Campus III - PB \\ ${ }^{4}$ Faculdade da Terra de Brasília - Brasília, DF \\ ${ }^{5}$ Universidade Estadual de Santa Catarina - Campus de Lajes, SC
}

\begin{abstract}
RESUMO
Analisaram-se as qualidades física, química e sensorial, bem como o perfil de ácidos graxos da carne de fêmeas suínas alimentadas com dietas com concentrações crescentes de ractopamina. Foram utilizadas 468 fêmeas, com peso inicial de $84,77 \pm 7,20 \mathrm{~kg}$, alojadas em 36 baias e alimentadas com dietas contendo $0,5,10$ ou $15 \mathrm{mg}$ de ractopamina $/ \mathrm{kg}$. Após o período de 28 dias, dois animais de cada baia, depois de passarem por 15 horas de jejum sólido, foram abatidos. Uma amostra do músculo Longissimus da meia carcaça direita foi colhida para se avaliar as características de qualidade da carne. Não houve efeito $(\mathrm{P}>0,05)$ da adição de ractopamina às dietas sobre $\mathrm{o} \mathrm{pH}$, capacidade de retenção de água, força de cisalhamento, cor e oxidação lipídica da carne. Observou-se efeito quadrático $(\mathrm{P}<0,05)$ para perdas por cocção da carne, e não foi observada diferença $(P>0,05)$ na análise sensorial da carne. Também não foi observado efeito $(\mathrm{P}>0,05)$ sobre a composição em ácidos graxos e sobre a relação entre ácidos graxos saturados:insaturados. A adição de até $15 \mathrm{mg}$ de ractopamina/kg de dieta não altera as características físicas, sensoriais e o perfil de ácidos graxos da carne de fêmeas suínas abatidas com $110 \mathrm{~kg}$ de peso.
\end{abstract}

Palavras-chave: carne suína, modificador de carcaça, qualidade de carne

\begin{abstract}
A study was conducted to evaluate the physical, chemical and sensorial quality and fat acids profile of meat from gilts fed diets containing increasing concentration of ractopamine. A total of 468 gilts with initial weight of $84.77 \pm 7.20 \mathrm{~kg}$ were allotted into 36 pens and fed diets containing $0,5,10$ or $15 \mathrm{mg}$ of ractopamine/kg. After an experimental period of 28 days, two animals from each pen were chosen and slaughtered after 15 hours of fasting. A sample of the Longissimus muscle was collected to evaluate the quality of the pork meat. There was no effect $(P>0.05)$ of ractopamine inclusion in $\mathrm{pH}$, water holding capacity, shear force, color and lipid oxidation. However, a quadratic trend was observed $(P<0.05)$ for cooking loss by increasing concentration of ractopamine in diets. For sensorial analysis of the Longissimus muscle, no differences were noted $(P>0.05)$. No effects were observed $(P>0.05)$ for fat acids profile and saturated and unsaturated fat acids ratio. In conclusion, the increase of up to $15 \mathrm{mg}$ of ractopamine/kg concentration in the diet does not change the physical and sensorial characteristics and the fat acids profile of meat from gilts slaughtered at $110 \mathrm{~kg}$ of body weight.
\end{abstract}

Keywords: carcass modifier, meat quality, pork meat

Recebido em 8 de abril de 2011

Aceito em 23 de maio de 2012

E-mail: pedrowatanabe@ufc.br

Projeto financiado pela FAPESP 


\section{INTRODUÇÃO}

A ractopamina é um agonista $\beta$ adrenérgico que vem sendo utilizado em dietas para suínos, com o intuito de melhorar a qualidade das carcaças, por proporcionar maior deposição muscular, menor deposição de gordura e, consequentemente, aumentar a quantidade de carne magra (Mills, 2002). Os principais efeitos da ractopamina sobre o metabolismo estão relacionados ao tecido muscular esquelético e à gordura corporal dos animais, havendo pouca influência sobre o metabolismo glicídico (Ramos e Silveira, 2000).

De acordo com Moloney e Beermann (1996), a diminuição da proteólise apresenta-se como fator importante para o aumento da quantidade de carne magra nas carcaças de animais alimentados com dietas contendo ractopamina, sendo comprovada por meio do decréscimo da excreção de 3-metil-histidina, produto resultante do catabolismo proteico. Sainz et al. (1993) afirmaram também que a adição de ractopamina em dietas para suínos promoveu aumento na quantidade de carne na carcaça, devido à menor ação da calpaína sobre a proteólise do músculo.

Com relação ao tecido adiposo, observa-se a diminuição da gordura corporal, particularmente a subcutânea e a intermuscular, em decorrência do uso de ractopamina em dietas para suínos (Willians et al., 1994; Carr et al., 2005), principalmente em virtude do efeito antilipogênico deste agonista (Quirke et al., 1988; Peters, 1990; Haese e Bünzen, 2005). Entretanto, em função destes mesmos efeitos metabólicos, a ractopamina também pode afetar as características qualitativas da carne, sendo um importante aspecto a ser considerado, tanto para a indústria quanto para o consumidor. Enquanto Carr et al. (2005) observaram redução na maciez da carne de suínos, alimentados com dietas contendo $10 \mathrm{mg}$ de ractopamina/kg de dieta, Weber et al. (2006) verificaram que a inclusão da mesma concentração do produto nas dietas para suínos não alterou os padrões de coloração, marmoreio e maciez da carne.

As divergências sobre o uso deste agonista $\beta$ adrenérgico sobre a qualidade da carne suína demonstram um possível efeito desfavorável, principalmente sobre a maciez da carne, que pode ser acentuado pela maior adição do produto
(Ramos e Silveira, 2002), limitando, assim, sua inclusão em dietas para suínos.

Assim, objetivou-se avaliar os efeitos do uso de concentrações crescentes de ractopamina na dieta sobre as características físicas e sensoriais e sobre o perfil de ácidos graxos da carne de fêmeas suínas.

\section{MATERIAL E MÉTODOS}

O experimento foi realizado em uma granja comercial e teve duração de 28 dias. Foram utilizadas 468 fêmeas, com média de peso inicial de $84,77 \pm 7,20 \mathrm{~kg}$, alojadas em 36 baias $(3,5 \times 4 \mathrm{~m})$ de piso compacto, equipadas com bebedouros tipo concha e comedouros lineares, as quais abrigavam 13 fêmeas suínas cada. Os animais foram distribuídos entre os tratamentos em um delineamento em blocos ao acaso, para controlar as diferenças de peso entre os animais das diferentes baias.

As dietas foram formuladas para atender às exigências nutricionais e energética mínimas indicadas por Rostagno et al. (2005), considerando-se a concentração energética de $3230 \mathrm{kcal} \mathrm{EM} / \mathrm{kg}$ de dieta, $16,20 \%$ de $\mathrm{PB}$ e $1,10 \%$ de lisina digestível, para fêmeas de alto potencial genético, havendo a substituição progressiva do inerte pelo produto comercial, o qual continha $2 \%$ de ractopamina. O teor de $1,10 \%$ de lisina digestível foi estabelecido pela maior exigência deste aminoácido, quando há adição de ractopamina na dieta (Xiao et al., 1999), sendo mantidas as proporções dos demais aminoácidos com base no conceito de proteína ideal (Rostagno et al., 2005). Na Tab. 1 encontram-se as composições centesimal, química e energética da dieta-controle. As dietas experimentais foram: DC - dietacontrole, composta principalmente por milho e farelo de soja; DC5 - dieta-controle contendo $5 \mathrm{mg}$ de ractopamina/kg; DC10 - dietacontrole contendo $10 \mathrm{mg}$ de ractopamina $/ \mathrm{kg}$; DC15 - dieta-controle contendo $15 \mathrm{mg}$ de ractopamina $/ \mathrm{kg}$.

Ao início do experimento, os animais de cada baia foram pesados individualmente $\mathrm{e}$ identificados por meio de brincos numerados. Após a pesagem, as quatro dietas experimentais foram distribuídas de acordo com o peso médio dos animais de cada baia. Ao final do 
experimento, dois animais de cada baia foram escolhidos na última pesagem antes do abate, considerando-se apenas aqueles que apresentavam o peso dentro do intervalo compreendido pela média \pm desvio-padrão do peso dos animais da baia, sendo, então, destinados ao abate, que ocorreu no dia seguinte à última pesagem. Os animais foram submetidos a jejum sólido, previamente ao abate de 15 horas. Após o abate, as carcaças foram serradas longitudinalmente ao meio e pesadas, sendo levadas à câmara fria, em temperatura de refrigeração $\left(4^{\circ} \mathrm{C}\right)$, permanecendo por 24 horas.

Tabela 1. Composição centesimal, química e energética da dieta-controle

\begin{tabular}{|c|c|}
\hline Ingrediente & $\%$ \\
\hline Milho & 77,59 \\
\hline Farelo de soja & 18,48 \\
\hline Fosfato bicálcico & 0,81 \\
\hline Calcário calcítico & 0,52 \\
\hline Sal comum & 0,31 \\
\hline $\mathrm{L}$ - Lisina. $\mathrm{HCl}(78,5 \%)$ & 0,63 \\
\hline DL - Metionina $(99 \%)$ & 0,16 \\
\hline $\mathrm{L}$ - Treonina $(98,5 \%)$ & 0,26 \\
\hline $\mathrm{L}-$ Triptofano $(98 \%)$ & 0,05 \\
\hline Suplemento vitamínico ${ }^{1}$ & 0,15 \\
\hline Suplemento mineral ${ }^{2}$ & 0,15 \\
\hline Inerte & 0,89 \\
\hline Total & 100,00 \\
\hline \multicolumn{2}{|l|}{ Composição química e energética $^{3}$} \\
\hline Energia metabolizável, kcal/kg & $3.230,00$ \\
\hline Proteína bruta, \% & 16,20 \\
\hline Lisina digestível, \% & 1,10 \\
\hline Metionina+Cistina digestível, \% & 0,62 \\
\hline Treonina digestível, $\%$ & 0,72 \\
\hline Triptofano digestível, \% & 0,19 \\
\hline Fósforo disponível, \% & 0,25 \\
\hline Cálcio, \% & 0,48 \\
\hline
\end{tabular}

${ }^{1}$ Suplemento vitamínico - quantidade por kg do produto: 2.500.000UI de vit. A; 500.000 UI vit. D3; 50mg de biotina; 50mg de colina; $10000 \mathrm{mg}$ de niacina; 3000mg de pantotenato de cálcio; $7 \mathrm{mg}$ de vit. B12; 1800mg de vit. B2; $7500 \mathrm{mg}$ de vit. E; $1000 \mathrm{mg}$ de vit. K3; ${ }^{2}$ Suplemento mineral - quantidade por kg do produto: $40.000 \mathrm{mg}$ de ferro; $35.000 \mathrm{mg}$ de cobre; $20.000 \mathrm{mg}$ de manganês; $40.000 \mathrm{mg}$ de zinco; 360mg de cobalto; $840 \mathrm{mg}$ de iodo; $120 \mathrm{mg}$ de selênio; ${ }^{3}$ Valores nutricionais dos ingredientes, propostos por Rostagno et al. (2005).

Da meia carcaça direita de cada animal, foi colhida uma amostra de aproximadamente $20 \mathrm{~cm}$ do músculo Longissimus, sendo retirada a camada de gordura adjacente ao músculo. Realizaram-se análises da capacidade de retenção de água, cor, $\mathrm{pH}$, perdas por cocção, força de cisalhamento e oxidação lipídica da carne in natura, submetidas à refrigeração por período próximo de 24 horas.

Uma amostra do músculo Longissimus foi destinada à quantificação dos ácidos graxos saturados, monoinsaturados e poli-insaturados. Foram realizadas extrações lipídicas por solubilização em clorofórmio-metanol (2:1), sendo determinado o conteúdo de lipídeos totais
(Bligh e Dyer, 1959), após secagem do extrato. Os extratos concentrados de lipídeos obtidos em rotoevaporador $\left(60^{\circ} \mathrm{C}\right)$ foram processados, sendo realizada a esterificação dos ácidos graxos (Bragnolo e Rodriguez-Amaya, 2002). Os extratos esterificados foram usados para determinação do perfil de ácidos graxos, por meio de cromatografia gasosa.

Para a análise sensorial, amostras do músculo Longissimus foram levadas ao forno à temperatura de $170^{\circ} \mathrm{C}$, até atingirem a temperatura interna de $75^{\circ} \mathrm{C}$. Após estarem assadas, foram cortadas em cubos de aproximadamente $2 \mathrm{~cm}^{3}$, embaladas individualmente em papel alumínio e transferidas 
para béqueres codificados e mantidos em banhomaria à temperatura de $45-50^{\circ} \mathrm{C}$. Para realização da análise, foram utilizados 30 provadores não treinados.

Utilizou-se, no teste descritivo, escala hedônica de nove pontos, considerando-se os atributos de sabor - sensação de gosto e odor liberados pela amostra durante a mastigação -, textura percepção da força necessária para o cisalhamento da amostra ao morder - e aceitação geral - somatório de todas as percepções sensoriais, expressando a opinião dos julgadores sobre a qualidade da carne -, conforme descrito por Dutcosky (1996). Os noves pontos da escala consistiam em: 1 - desgostei muitíssimo; 2 desgostei muito; 3 - desgostei regular; 4 desgostei ligeiramente; 5 - indiferente; 6 - gostei ligeiramente; 7 - gostei regular; 8 - gostei muito e 9 - gostei muitíssimo.
Considerou-se como unidade experimental a média dos dois animais de cada baia, e os dados obtidos, após serem analisados quanto à distribuição dos erros - teste de Cramer VonMises a 5\%, de acordo com Everitt (1998) -, foram submetidos à análise de variância, utilizando-se o pacote PROC GLM do programa estatístico SAS, sendo realizadas regressões lineares múltiplas até o terceiro grau. Para os dados da análise sensorial, as notas obtidas para cada tratamento foram comparadas pelo teste de Tukey (5\%).

\section{RESULTADOS E DISCUSSÃO}

Não houve efeito $(\mathrm{P}>0,05)$ da adição de ractopamina nas dietas sobre o $\mathrm{pH}$, a capacidade de retenção de água, a força de cisalhamento, a cor $\left(\mathrm{L}^{*}, \mathrm{a}^{*}, \mathrm{~b}^{*}\right)$ e a oxidação lipídica da carne de fêmeas suínas (Tab. 2).

Tabela 2. Valores de pH, capacidade de retenção de água (CRA), força de cisalhamento (FC), perdas por cocção (PPC), cor ( $\mathrm{L}^{*}, \mathrm{a}^{*}$ e $\mathrm{b}^{*}$ ) e oxidação lipídica do músculo Longissimus de fêmeas suínas alimentadas com diferentes concentrações de ractopamina nas dietas

\begin{tabular}{|c|c|c|c|c|c|c|c|}
\hline \multirow{2}{*}{ Qualidade da carne } & \multicolumn{4}{|c|}{ Ractopamina, mg/kg } & \multirow{2}{*}{$\mathrm{CV}, \%$} & \multirow{2}{*}{ Regressão } & \multirow{2}{*}{$\mathrm{P}$} \\
\hline & 0 & 5 & 10 & 15 & & & \\
\hline $\mathrm{pH}$ & 5,59 & 5,71 & 5,62 & 5,75 & 3,33 & - & 0,1670 \\
\hline CRA, $\%$ & 68,89 & 69,21 & 67,77 & 68,23 & 2,57 & - & 0,2253 \\
\hline $\mathrm{FC}, \mathrm{kgF} / \mathrm{cm}^{2}$ & 1,46 & 1,32 & 1,62 & 1,50 & 20,53 & - & 0,3784 \\
\hline PPC, \% & 29,34 & 31,49 & 33,66 & 33,76 & 9,00 & Quadrática & 0,0187 \\
\hline \multicolumn{8}{|l|}{ Cor } \\
\hline $\mathrm{L}^{*}$ & 49,89 & 50,82 & 48,17 & 46,47 & 9,54 & - & 0,0899 \\
\hline$a^{*}$ & 7,87 & 7,34 & 8,03 & 6,96 & 16,60 & - & 0,3258 \\
\hline$b^{*}$ & 4,26 & 3,64 & 3,15 & 3,14 & 39,87 & - & 0,0939 \\
\hline Oxidação lipídica, mg/kg & 0,045 & 0,045 & 0,045 & 0,034 & 23,52 & - & 0,2152 \\
\hline
\end{tabular}

Observou-se efeito quadrático $(\mathrm{P}=0,0187)$ sobre as perdas por cocção da carne, com as crescentes concentrações de ractopamina adicionadas às dietas (Fig. 1), sendo o maior valor de perdas por cocção estimado para a concentração de $11,57 \mathrm{mg}$ de ractopamina/kg de dieta. Fernandes (1995) afirmou que a utilização de ractopamina em dietas para suínos provocou aumento na quantidade de água nas carcaças, refletindo-se, assim, em menor capacidade de retenção de água. Tal efeito pode ser considerado negativo para a indústria de processamento e também para os consumidores, visto que resulta em menor rendimento em função das perdas, além de interferir na maciez e no rendimento da carne (Rosa et al., 2008).
Apesar de não terem sido observadas alterações sobre os parâmetros de cor, Ferreira e Bastos (1994) afirmaram que a carne oriunda de animais alimentados com dietas contendo ractopamina apresenta-se mais escura, devido à estimulação ante-mortem da glicogenólise, levando à redução do glicogênio muscular e limitando a acidificação normal post-mortem. Almeida et al. (2010) também não observaram efeito da inclusão de ractopamina sobre os valores de L na carne de suínos, embora tenham encontrado menor teor de vermelho encontrado, sugerindo que a inclusão deste agonista nas dietas de suínos reduziu a quantidade de mioglobina oxigenada na carne, tornando-a com coloração menos vermelha. 


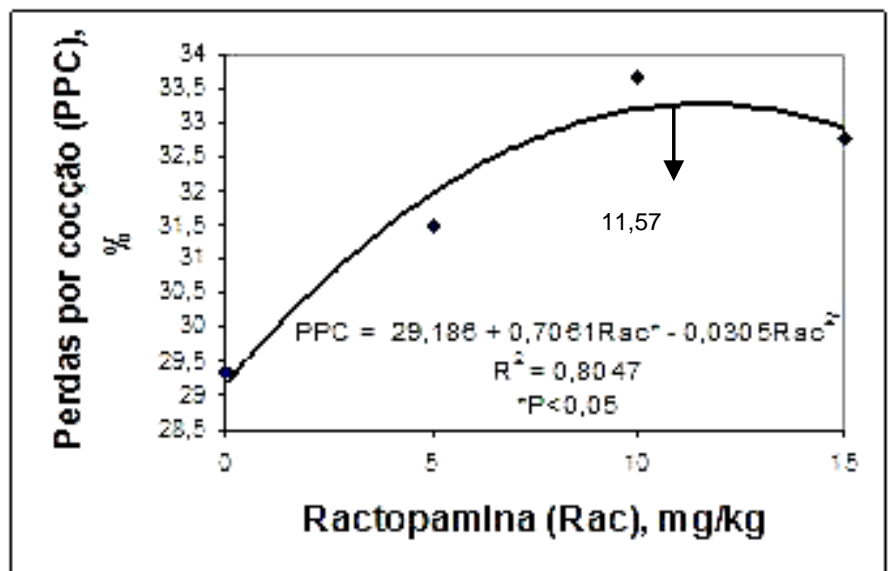

Figura 1. Perdas por cocção do músculo Longissimus de fêmeas suínas, em função da concentração de ractopamina na dieta.

Em relação à análise sensorial das amostras do músculo Longissimus de fêmeas suínas alimentadas com diferentes concentrações de ractopamina na dieta, não foi observada diferença $(\mathrm{P}>0,05)$ entre as amostras para os parâmetros de sabor, textura e aceitação geral (Tab. 3).

Tabela 3. Análise sensorial das amostras do músculo Longissimus de fêmeas suínas alimentadas com diferentes concentrações de ractopamina nas dietas

\begin{tabular}{lcccccc} 
& \multicolumn{4}{c}{ Ractopamina, $\mathrm{mg} / \mathrm{kg}$} & \multirow{2}{*}{$\mathrm{CV}, \%$} & $\mathrm{P}$ \\
\cline { 2 - 5 } & 0 & 5 & 10 & 15 & & \\
\hline Sabor & 7,29 & 7,46 & 7,16 & 7,58 & 14,83 & $>0,05$ \\
Textura & 7,58 & 7,20 & 7,20 & 7,00 & 16,48 & $>0,05$ \\
Aceitação geral & 7,17 & 7,21 & 7,17 & 7,54 & 15,21 & $>0,05$ \\
\hline
\end{tabular}

De acordo com Ramos e Silveira (2002), independentemente dos hábitos alimentares das diferentes populações, quando se trata de consumo de carne, os fatores de maior relevância para o consumidor são maciez e sabor, juntamente com suculência e odor. Associada a estes fatores, a aparência do produto também tem importância, embora não tenha sido avaliada no presente trabalho.

Em relação ao sabor, como a ractopamina tem efeito direto sobre a deposição de gordura subcutânea e intermuscular (Willians et al., 1994; Carr et al., 2005), sua utilização na alimentação de suínos pode trazer como consequência alguma alteração no sabor da carne. Entretanto, não foi observado tal resultado, possivelmente em razão da manutenção do perfil dos ácidos graxos. Da mesma forma, a textura avaliada pela análise sensorial não foi afetada pelo aumento das perdas por cocção da carne.
Embora Carr et al. (2005) tenham observado redução na maciez da carne de suínos alimentados com dietas contendo $10 \mathrm{mg}$ de ractopamina $/ \mathrm{kg}$, não foi verificada tal diferença para esta variável no presente estudo, o que concordou com os resultados encontrados por Weber et al. (2006).

Jones et al. (1985) relataram que o uso de agonistas $\beta$ adrenérgicos nas dietas leva à produção de uma carne suína mais dura. Warris et al. (1991), ao compararem os resultados da análise sensorial com a avaliação mecânica da força de cisalhamento, em carne de suínos alimentados com dietas contendo agonistas $\beta$ adrenérgicos, observaram aumento da força de cisalhamento, porém não detectado pela análise sensorial. De acordo com Moloney e Allen (1992), o efeito da adição de agonistas $\beta$ adrenérgicos nas dietas sobre a maciez da carne não é semelhante para todas as espécies, sendo 
menos evidente na carne de suínos do que nas de bovinos, ovinos e frangos.

Não foi observado efeito $(\mathrm{P}>0,05)$ da adição de ractopamina nas dietas sobre a composição em ácidos graxos e a proporção de ácidos graxos saturados e insaturados das amostras do músculo Longissimus de fêmeas suínas (Tab. 4).

Tabela 4. Teores de ácidos graxos das amostras do músculo Longissimus de fêmeas suínas alimentadas com diferentes concentrações de ractopamina nas dietas

\begin{tabular}{|c|c|c|c|c|c|c|c|}
\hline \multirow[b]{2}{*}{ Ácido graxo, \% } & \multicolumn{4}{|c|}{ Ractopamina, mg/kg } & \multirow{2}{*}{$\mathrm{CV}, \%$} & \multirow{2}{*}{ Regressão } & \multirow{2}{*}{$\mathrm{P}$} \\
\hline & 0 & 5 & 10 & 15 & & & \\
\hline Cáprico (10:0) & 0,09 & 0,10 & 0,08 & 0,09 & 17,28 & - & 0,3078 \\
\hline Láurico (12:0) & 0,07 & 0,07 & 0,07 & 0,07 & 17,38 & - & 0,5337 \\
\hline Tridecanoico (13:0) & 0,18 & 0,26 & 0,16 & 0,28 & 15,02 & - & 0,9192 \\
\hline Mirístico (14:0) & 1,10 & 1,13 & 1,19 & 1,15 & 13,94 & - & 0,3815 \\
\hline Pentadecanoico (15:0) & 0,13 & 0,11 & 0,10 & 0,11 & 46,64 & - & 0,4220 \\
\hline Palmítico (16:0) & 25,16 & 24,33 & 25,03 & 24,49 & 5,16 & - & 0,5179 \\
\hline Palmitoleico (16:1) & 2,29 & 2,50 & 2,37 & 2,25 & 15,08 & - & 0,6612 \\
\hline Pentadecanoico (17:0) & 0,54 & 0,49 & 0,49 & 0,55 & 29,91 & - & 0,3557 \\
\hline Pentadecenoico (17:1) & 0,35 & 0,45 & 0,38 & 0,44 & 27,37 & - & 0,4519 \\
\hline Esteárico (18:0) & 12,02 & 11,13 & 11,96 & 12,06 & 10,87 & - & 0,3299 \\
\hline Oleico $(18: \ln 9 \mathrm{c})$ & 38,42 & 41,23 & 41,10 & 40,55 & 10,34 & - & 0,2080 \\
\hline Linoleico $(18: 2 n 6 c)$ & 17,17 & 15,59 & 14,86 & 15,15 & 26,62 & - & 0,4276 \\
\hline$\gamma$-linolênico (18:3n6) & 0,10 & 0,10 & 0,09 & 0,15 & 82,64 & - & 0,5505 \\
\hline$\alpha$-linolênico (18:3n3) & 0,54 & 0,52 & 0,49 & 0,50 & 15,66 & - & 0,4803 \\
\hline Eicosanoico $(20: 1 n 9)$ & 0,45 & 0,49 & 0,53 & 0,52 & 33,21 & - & 0,5864 \\
\hline Eicosadienoico $(20: 2)$ & 0,45 & 0,44 & 0,41 & 0,39 & 24,82 & - & 0,9962 \\
\hline Aracdônico (20:4n6) & 0,94 & 0,79 & 0,68 & 1,26 & 64,92 & - & 0,1289 \\
\hline Saturados & 39,28 & 37,89 & 39,09 & 38,80 & 5,46 & - & 0,9387 \\
\hline Insaturados & 60,72 & 62,11 & 60,91 & 61,20 & 3,46 & - & 0,8398 \\
\hline Monoinsaturados & 41,52 & 44,67 & 44,38 & 43,76 & 10,11 & - & 0,3617 \\
\hline Poli-insaturados & 19,20 & 17,44 & 16,53 & 17,44 & 27,04 & - & 0,4184 \\
\hline Insaturados/saturados & 1,55 & 1,65 & 1,57 & 1,58 & 8,88 & - & 0,9509 \\
\hline Relação linoleico/linolênico & 26,83 & 25,14 & 25,62 & 23,31 & 73,61 & - & 0,1935 \\
\hline
\end{tabular}

Almeida et al. (2010) observaram que a adição de $5 \mathrm{mg} / \mathrm{kg}$ de ractopamina reduziu o teor de amarelo na carne de suínos machos castrados e fêmeas, podendo ser um indicativo de mudanças na composição de ácidos graxos da gordura intramuscular com o uso deste aditivo. No entanto, os resultados apresentados neste trabalho assemelham-se aos obtidos por Weber et al. (2006), que, ao avaliarem a adição de $10 \mathrm{mg}$ de ractopamina/kg de dieta, para fêmeas suínas com alto potencial para acréscimo de tecido magro, notaram que este agonista reduziu a quantidade de lipídeo total contido no músculo, porém sem alterar o perfil de ácidos graxos da gordura intramuscular ou mesmo a avaliação visual da marmorização. Esses mesmos autores também afirmaram que a ractopamina não alterou o perfil de ácidos graxos da gordura da barriga de fêmeas suínas, apresentando valores ideais preconizados pela indústria de processamento da carne.

Embora Ramos e Silveira (2002) tenham observado que a adição de agonistas $\beta$ adrenérgicos em dietas para bovinos alterou o perfil de ácidos graxos, com aumento da relação entre os insaturados e os saturados em decorrência do aumento do ácido graxo linoleico, no presente trabalho não foi observado tal efeito para a carne suína. $\mathrm{O}$ aumento da relação entre ácidos graxos insaturados e saturados, mesmo podendo tornar a carne suína um alimento ainda mais saudável para o homem, pode torná-la uma matéria-prima ou produto menos vantajoso para a indústria de transformação, devido à maior susceptibilidade à oxidação dessa gordura contida na carne. 


\section{CONCLUSÃO}

Conclui-se que a adição de até $15 \mathrm{mg}$ de ractopamina/kg de dieta não altera as características físicas, sensoriais e o perfil de ácidos graxos da carne de fêmeas suínas abatidas com $110 \mathrm{~kg}$ de peso.

\section{REFERÊNCIAS}

ALMEIDA, V.V.; BERENCHTEIN, B.; COSTA, L.B. et al. Ractopamina, cromometionina e suas combinações como aditivos modificadores do metabolismo de suínos em crescimento e terminação. Rev. Bras. Zootec., v.39, p.1969-1977, 2010.

BLIGH, E.G.; DYER, W.J. A rapid method of total lipid extration and purification. Can. J. Bioch. Phys., v.37, p.911-917, 1959.

BRAGNOLO, N.; RODRIGUEZ-AMAYA, D.B. Teores de colesterol, lipídeos totais e ácidos graxos em cortes de carne suína. Cienc. Tecnol. Aliment., v.22, p.98-104, 2002.

CARR, S.N.; RINCKER, P.J.; KILLEFER, J. et al. Effects of different cereal grains and ractopamine hydrochloride on performance, carcass characteristics, and fat quality in latefinishing pigs. J. Anim. Sci., v.83, p.223-230, 2005

DUTCOSKY, S.D. Análise sensorial de alimentos. Curitiba: Champagnat, 1996. 123p.

EVERITT, B.S. The Cambridge dictionary of statistics. Cambridge: Cambridge University Press, 1998. 360p.

FERNANDES, T. Utilização de beta-agonistas como estimuladores do crescimento em animais destinados à produção de carne. In: IPPA Instituto de Protecção da Produção AgroAlimentar. Utilização dos promotores de crescimento (beta-agonistas) em animais destinados à produção de carne. Lisboa: IPPA, 1995. p.39-49.

FERREIRA, M.; BASTOS, M.L. Os agonistas $\beta 2$ na produção de carne. Rev. Port. Farm., v.165, p.91-96, 1994.

HAESE, D.; BÜNZEN, S. Ractopamina. Rev. Elet. Nutri., v.2, p.176-182, 2005. Disponível em: <http://www.nutritime.com.br/arquivos_internos/ artigos/019V2N2P176_182_MAR2005.pdf>.

Acessado em: 7 Abr. 2012.
JONES, R.W.; EASTER, R.A.; McKEITH, F.K. et al. Effect of the $\beta$-adrenergic agonist cimaterol on the growth and carcass characteristics of finishing swine. J. Anim. Sci., v.61, p.905-913, 1985.

MILLS, S.E. Biological basis of the ractopamine response. J. Anim. Sci., v.80, p.E28-E32, 2002.

MOLONEY, A.P.; ALLEN, P. Repartioning effects of $\beta$-adrenergic agonists in meat. In: KUIPER, H.A., HOOGENBOOM, L.A.P. In vitro toxicological studies and real time analysis of residues in food, 8. Wageningen: Wageningen Press, 1992. p.89-101.

MOLONEY, A.P.; BEERMANN, D.H. Mechanisms by wich _-adrenergic agonists alter growth and body composition in ruminants. In: ENNE, G.; KUIPER, H.A.; VALENTINI, A. Residues of veterinary drugs and mycotoxins in animal products. Wageningen: Wageningen Press, 1996. p.124-136.

PETERS, A.R. Beta-agonists and pig production. Pig News and Information, v.11, p.519-525, 1990.

QUIRKE, J.F.; ALLEN, P.; MOLONEY, A.P. et al. Effects of the beta-agonist cimaterol on blood metabolite and hormone concentrations, growth and carcass composition in finishing Friesian steers. J. Anim. Physiol. Anim. Nutrit., v.60, p.128-136, 1988.

RAMOS, F.; SILVEIRA, M.I.N. Agonistas adrenérgicos $\beta 2$ e produção animal. I Mecanismo de acção. Rev. Port. Cienc. Vet., v.95, p.99-110, 2000

RAMOS, F.; SILVEIRA, M.I.N. Agonistas adrenérgicos $\beta 2$ e produção animal. III - Efeitos zootécnicos e qualidade da carne. Rev. Port. Cienc. Vet., v.97, p.51-62, 2002.

ROSA, A.F.; GOMES, J.D.F.; MARTELLI, M.R. et al. Qualidade da carne de suínos de três linhagens genéticas comerciais em diferentes pesos de abate. Cienc. Rural, v.38, p.1394-1401, 2008.

ROSTAGNO, H.S.; ALBINO, L.F.T.; DONZELE, J.L. et al. Tabelas brasileiras para aves e suínos - Composição de alimentos $e$ exigências nutricionais. Viçosa: Imprensa Universitária/UFV, 2005. 141p. 
SAINZ, R.D.; KIM, Y.S.; DUNSHEA, F.R. et al. Effects of ractopamine in pig muscles: histology, calpains and $\beta$-adrenergic receptors. Aust. J. Agric. Res., v.44, p.1441-1448, 1993.

WARRIS, P.D.; NUTE, G.R.; ROLPH, T.P. et al. Eating quality of meat from pigs given the beta-adrenergic agonist salbutamol. Meat Scie., v.30, p.75-80, 1991.

WEBER, T.E.; RICHERT, B.T.; BELURY, M.A. et al. Evaluation of the effects of dietary fat, conjugated linoleic acid, and ractopamine on growth performance, pork quality, and fatty acid profiles in genetically lean gilts. J. Anim. Sci., v.84, p.720-732, 2006.
WILLIANS, N.H.; CLINE, T.R.; SCHINCKEL, A.P. et al. The impact of ractopamine, energy intake and dietary fat on finisher pig growth performance and carcass merit. J. Anim. Sci., v.72, p.3152-3162, 1994.

XIAO, R.J.; XU, Z.R.; CHEN, H.L. Effects of ractopamine at different dietary protein levels on growth performance and carcass characteristics in finishing pigs. Anim. Feed Scie. Technol., v.79, p.119-127, 1999. 